\title{
Biodegradation of PP and PE Blended with PHBV in Soil Samples
}

\author{
SUELY PATRICIA COSTA GONÇALVES, SANDRA MARA MARTINS FRANCHETTI \\ Department of Biochemistry and Microbiology, UNESP - São Paulo State University, Rio Claro, SP, Brazil \\ Correspondence to: Sandra Mara Martins Franchetti; e-mail: samaramf@rc.unesp.br. \\ Received: June 30, 2014 \\ Accepted: September 20, 2014
}

\begin{abstract}
This work studied the biodegradation of polyethylene/poly(hydroxybutyrate-co-hydroxyvalerate) (PE/PHBV) and polypropylene/PHBV (PP/PHBV) films, by respirometry in soil, using biometric flasks. Additionally, the characteristics of the soil were measured by $\mathrm{pH}$, moisture, organic matter content, and quantification of microorganisms. The soil analysis showed that the two blends inhibited the soil bacteria activity and stimulated the growth of fungi. The PE/PHBV (80/20) blend is more susceptible to the microbial action in the soil than the PP/PHBV (80/20) blend. The blends showed higher biodegradation in the PHBV amorphous phase, due to consumption of ester groups, leading to rearrangement of the crystalline phase of PHBV fraction. On the basis of quantification of $\mathrm{CO}_{2}$, the PE/PHBV (80/20) film showed approximately $7 \%$ biodegradation, and the beginning occurred in a period of 60 days. Moreover, the employed methods Fourier transform infrared spectroscopy and X-ray diffraction completed the information obtained by the respirometry method, showing evident changes in the polymer chains structure and crystallinity, respectively. @ 2014 Wiley Periodicals, Inc. Adv Polym Technol 2015, 34, 21486; View this article online at wileyonlinelibrary.com.

DOI $10.1002 / a d v .21486$
\end{abstract}

KEY WORDS: Blends, FT-IR, X-ray, Respirometry, Soil

\section{Introduction}

$\mathbf{T}$ he use of polymeric materials in daily life has increased dramatically in recent decades. After disposal, high levels of plastic debris persist in the environment, which generates several cumulative effects. The biodegradability of polymeric materials is dependent on the reaction of their structure in the presence of degradative microbial populations and on environmental conditions that favor microbial growth. The attack of microorganisms on polymeric materials depends on the specificity of the microorganisms, the chemical and physical properties of the materials and environmental conditions. ${ }^{1}$

In general, organic and synthetic compounds undergo decomposition in the soil through the process of aerobic soil respiration, which causes oxidation (loss of electrons) of the substrate, which can oxidize completely into $\mathrm{CO}_{2}$, with greater production of adenosine triphosphate. ${ }^{2}$ Therefore, the assessment of microbial respiration is one of the most widely used parameters to quantify the activity of soil microbes.

Several analytical methods for monitoring the biodegradation of polymers and standards have been established in order to standardize the procedures involved in biodegradation. These standards are commonly used to measure the $\mathrm{CO}_{2}$ released in aerobic environments, sewage effluents, activated sludge,

Contract grant sponsor: Capes-PNPD (2255/2009). and controlled composting. ${ }^{3-7}$ Although these testing methods share the same principles, they differ in the composition of the medium, inoculum, and the technique to measure the evolution of gas. In most tests, a conversion of $60-90 \%$ of the substrate to $\mathrm{CO}_{2}$ is expected to occur within 6 months, indicating the biodegradability of polymeric materials. ${ }^{8}$

However, little is known about the properties of the soil and parameters used. Soil is a complex ecosystem that encompasses an enormous diversity of organisms belonging to different taxonomic and physiological groups that interact at different levels within the community. ${ }^{9}$ The parameters attributed to soil quality enabled the evaluation of the physical, chemical, and biological properties of the soil in order to gain an understanding of the polymer biodegradation process.

Polyolefins such as polypropylene (PP) and polyethylene (PE) are the most widely used synthetic petrochemical-based polymeric materials, due to their ease of processing into various products, including packaging materials and equipments ${ }^{10}$ and good mechanical properties. Since synthetic polymers are difficult to biodegrade, one strategy for addressing this issue is to use blends or bio-based composite materials whose properties allow the reduction of the environmental impact caused by synthetic polymers. $^{11}$

Poly(hydroxybutyrate) (PHB) is a crystalline thermoplastic produced from renewable resources such as microbial organisms, ${ }^{12}$ in addition to being biodegradable in natural environments. ${ }^{13}$ A study on the blend properties of poly (hydroxybutyrate-co-hydroxyvalerate) (PHBV) and polylactide 
(PLA) showed that blends of PHBV/PLA are not miscible. The morphological analyses indicated that increasing the PHBV content in the polymer blends results in increasing the PLA crystallinity, as the finely dispersed PHBV crystals act as a filler and a nucleating agent for PLA. ${ }^{14}$ Other PHBV blends has been investigated such as with $\mathrm{PP}$ and PE, showing the effect of the degradable polymer on the synthetic polymers. ${ }^{15-17}$ According Massoud et al., ${ }^{17}$ the attachment of microorganisms on the PP/PHBV blend caused the oxidation process, resulting in the formation of different functional groups, i.e., alcohols, aldehydes, ketones, carboxyls, and the metabolites that are used by microbial cells.

Gómez and Michel $^{18}$ studied the relative biodegradability of a range of polymeric materials and natural fiber composites used for various commercial applications by measuring the average carbon $\left(\mathrm{CO}_{2}\right.$ and or $\left.\mathrm{CH}_{4}\right)$ mineralized from each treatment under composting, soil incubation, and anaerobic digestion conditions. The results showed that during 660 days soil incubation, substantial mineralization was observed for polyhydroxyalkanoate plastics, starch-based plastics, and materials made from compost. No significant degradation was observed for PE or PP plastics or the same plastics amended with commercial additives meant to confer biodegradability.

The combination of renewable resources polymers with synthetic polymers and the effect of properties of the soil during the biodegradation process may have influence on the biodegradation of the polymeric material. In this case, we have the polyolefins with excellent barrier properties, but difficult to degrade ${ }^{19}$ in contrast, the PHBV is susceptible to microbial action, especially if the HV content increases in the copolymer, causing crystallinity decrease. ${ }^{20,21}$ This study evaluated the condition of soil before and after respirometric tests and its influence on the biodegradation of PP/PHBV (80/20) and PE/PHBV $(80 / 20)$ blends.

\section{Materials and Methods}

\section{POLYMERS}

The polymeric materials used in this study were PP (HP $550 ; M_{\mathrm{w}}=145,000 \mathrm{~g} / \mathrm{mol}$, supplied by Braskem, São Paulo, Brazil), PE (BP-681/59, supplied by Braskem, São Paulo, Brazil). The polymers were mixed for $15 \mathrm{~min}$ in a Thermo Haake rheometer operating at $170^{\circ} \mathrm{C}$ and $60 \mathrm{rpm}$ (Department of Metallurgical and Materials Engineering, University of São Paulo, Brazil). The PP/PHBV and PE/PHBV (80/20, w/w) blends (granules) were compression molded for $3 \mathrm{~min}$ at $170^{\circ} \mathrm{C}$ between two aluminum sheets in a hot hydraulic press. All the films thus prepared showed an average thickness of $100 \mu \mathrm{m}$.

\section{FOURIER TRANSFORY INFRARED SPECTROSCOPY}

Infrared spectra were analyzed using a Shimadzu IRPrestige21 FTIR spectrometer with a resolution of 4 and $400-4000 \mathrm{~cm}^{-1}$. The Fourier transform infrared spectroscopy
(FTIR) band intensities were determined from the corrected profiles, using Lorentz deconvolution software (Shimadzu).

\section{X-RAY DIFFRACTION}

X-ray diffraction (XRD) measurements were taken using a Rigaku RU-200B diffractometer (belonging to IFSC/USP, São Carlos, SP, Brazil) operating at $50 \mathrm{kV}$ and $100 \mathrm{~mA}$ using a $\mathrm{CuK} \alpha$ radiation wavelength of $1.54 \mathrm{~A}$ as the $\mathrm{X}$-ray source. Diffraction patterns were recorded in the range of $2 \theta=10-35^{\circ}$ at a scan speed of $0.36 / \mathrm{min}$ at room temperature.

\section{SCANNING ELECTRON MICROSCOPY}

Scanning electron microscopy (SEM) was used to investigate the effects of biodegradation on the morphology of polymers films before and after biodegradation. The samples were prepared using conventional gold sputter coating and analyzed under a Zeiss DSM 940-A scanning electron microscope, using an acceleration voltage of $4 \mathrm{keV}$.

\section{SOIL}

Soil samples for the biodegradation tests were collected from a garden area (São Paulo State University, Rio Claro, SP, Brazil; $22^{\circ} 23^{\prime} 45^{\prime \prime} \mathrm{S}, 47^{\circ} 32^{\prime} 35^{\prime \prime} \mathrm{W}$ ) and from the top 15-cm depth. The soil was sifted through a 3-mm sieve and the sifted particles were used in the tests. According to the Köppen classification, the soil used was taken from a region that has a Cwa climate, with annual pluvial precipitation of $1366.8 \mathrm{~mm}$ and average annual temperature of $21.6^{\circ} \mathrm{C} .^{22}$

\section{SOIL ANALYSIS}

Soil samples were analyzed by measuring several physicochemical properties (organic matter, moisture content, $\mathrm{pH}$, quantification of microorganisms, and toxicity) after 180 days of incubation of the polymer in the soil. The $\mathrm{pH}$ of the soil was determined in $0.01 \mathrm{M}$ of $\mathrm{CaCl}_{2}(1: 2.5, \mathrm{w}: \mathrm{v}){ }^{23}$ The soil sample moisture content was determined by oven dry at $105 \pm 3^{\circ} \mathrm{C}$ for 24 h. $^{23}$

Soil's organic matter content was determined based on the method of combustion of organic matter in a muffle furnace. ${ }^{24}$ According to Pereira et al., ${ }^{24}$ determining the organic matter by the combustion method is satisfactory for soil samples with high organic carbon content.

The number of bacteria and fungi was determined by using plate count agar to enumerate bacteria and potato dextrose agar (PDA) supplemented with chloramphenicol (PDAchloramphenicol) to enumerate fungi growing on Petri dishes, which were both incubated at $30^{\circ} \mathrm{C}$ for $48 \mathrm{~h} .^{25}$

\section{BIODEGRADATION TEST-RESPIROMETRIC TEST}

Biometer flasks were used for the biodegradation tests, as originally suggested by Bartha and Pramer. ${ }^{26}$ Each biometer flask was filled with $50 \mathrm{~g}$ of soil and the moisture content was adjusted ( $60 \%$ field capacity), after which the polymer films were inserted (Fig. 1). The flasks were incubated at $28 \pm 2^{\circ} \mathrm{C}$, and $\mathrm{CO}_{2}$ 
production was measured volumetrically at intervals of approximately $24 \mathrm{~h}$ for 180 days.

The amount of $\mathrm{CO}_{2}$ generated by the samples during the respirometric test was calculated according to Eq. (1) (adapted from ISO 14855), ${ }^{27}$ where $V_{\mathrm{A}}$ is the volume of $\mathrm{HCl}$ used for titration.

$$
\mathrm{mCO}_{2}(\mathrm{mg})=\left\{[\mathrm{KOH}] /[\mathrm{HCl}] \times 10-V_{\mathrm{A}}\right\} \times[\mathrm{HCl}] \times 44
$$

The calculations to determine the amount of $\mathrm{CO}_{2}$ generated by the samples and their percentage of biodegradation during the respirometric test (Eqs. (2) and (3) were based on the ISO 14855 standard. ${ }^{27}$ The $\mathrm{CO}_{2}$ produced by biodegradation was determined from the difference between the values of $\mathrm{CO}_{2}$ produced in the flask containing the soil/polymer sample and the control flask (soil). The percentage of biodegradation of each sample was determined based on the ratio of the amount of $\mathrm{CO}_{2}$ produced by biodegradation of the material to the theoretical amount of $\mathrm{CO}_{2}\left(\mathrm{ThCO}_{2}\right)$ released by it, ${ }^{21}$ where " $m$ " is the mass of the film $(\mathrm{mg})$ and $X_{\mathrm{c}}$ is the quantity of carbon in the film (in this case based on its chemical formula).

$$
\mathrm{ThCO}_{2}=m \times X_{\mathrm{C}} \times(44 / 12)
$$

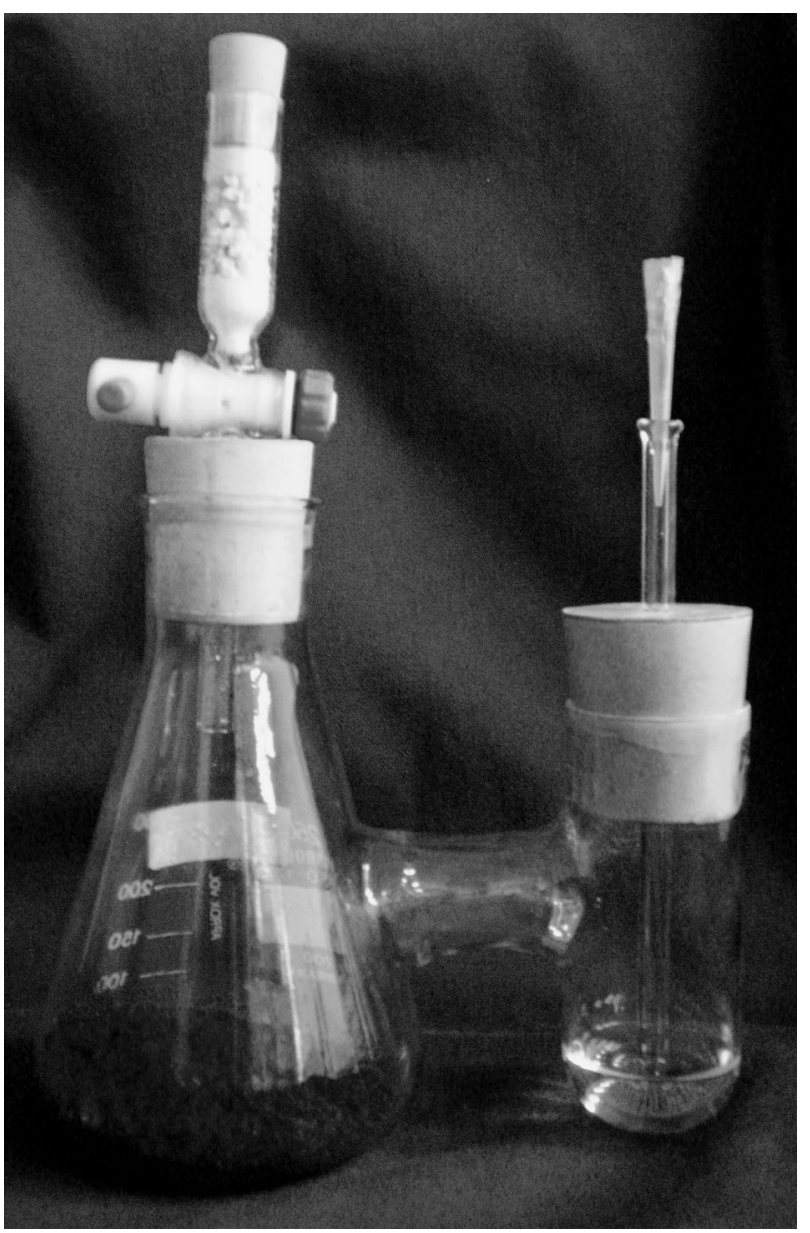

FIGURE 1. Biometer flask.
\%Biodegradation $=\left(m \mathrm{CO}_{2} / \mathrm{ThCO}_{2}\right) \times 100$

\section{Results and Discussion}

Table I presents the results of soil samples after 180 days of incubation of each tested blend in the biometer flask. After the biodegradation test, the $\mathrm{pH}$ of the soil in the flasks was 6.7 and 6.6, respectively, for control soil and blends. The amount of organic matter after the biodegradation test showed a variation of about $5 \%$ in the control soil and 3\% in the blends, compared with the original soil. The moisture content of soil samples after degradation varied according to the material contained in the biometer flasks.

Changes in the soil microbial community after biodegradation were dependent on the type of polymer. The bacterial population in the soil containing PP/PHBV and PE/PHBV decreased. However, the fungal population increased after 180 days of biodegradation; thus, in this case especially, these two factors along with the soil conditions favored the biodegradation process.

Microbial activity is influenced by several variables such as temperature, moisture, availability of nutrients, and input of organic matter, which are closely related to geographical coordinates and climate. ${ }^{28}$ Soil's water content is also essential for the microorganisms because it affects the intracellular metabolism, the movement of nutrients, toxic substances, and adherence to clay particles. ${ }^{29}$ Another important factor in microbial growth is soil's $\mathrm{pH}$, which can directly affect the metabolism, membrane permeability, and adsorption, or indirectly affect the physiology and solubility of toxic elements. ${ }^{2}$

Other related works show different results depending on the soil conditions and the polymer type. The degradation of a-PHB, binary blends with natural PHB (n-PHB), and poly(L-lactic acid) (PLLA), respectively, were investigated in the soil by Rytcher et al. ${ }^{30}$ Soil used in the experiments had a composition of $83 \%$ sand, $11 \%$ dust, and $6 \%$ loam, with average moisture of $15 \%$ and temperature of $22 \pm 2{ }^{\circ} \mathrm{C}$. During the experiment, the number of all tested microorganisms decreased slowly with the time of degradation. However, in the soil with an a-PHB/n-PHB blend after 42 and 70 days, an increase in the number of bacteria has been observed; and in the soil with PLLA and a-PHB/PLLA films, there have been no changes were observed in bacterial population during the incubation time. After a specified period of polymeric samples degradation indicated a slight increase in both acidity and salinity. The authors conclude that the addition of a-PHB accelerates the process of degradation of natural PHB, and in the presence of mineral fertilizer, the erosion of all samples occurs faster than that without fertilizer. ${ }^{30}$

Weng et al. $^{31}$ studied the biodegradation of the $\mathrm{P}(3 \mathrm{HB}, 4 \mathrm{HB}) / \mathrm{PLA}$ blends with different compositions at different depths in real soil environments. The degraded residues of various samples demonstrated that $\mathrm{P}(3 \mathrm{HB}, 4 \mathrm{HB})$ was biodegraded into small molecular weight acids caused by erosion of microorganisms. The degradation of PLA buried in 20 or $40 \mathrm{~cm}$ of soil was aerobic and anaerobic biodegradation, respectively. The degradation of PHA was caused by bacteria-catalyzed 
TABLE I

Properties of the Soil Used in the Respirometric Tests

\begin{tabular}{lcccrc}
\hline Material & $\mathrm{pH}\left(\mathrm{CaCl}_{2}\right)( \pm 0.3)$ & Organic Matter $(\mathrm{g} / \mathrm{kg})( \pm 16.2)$ & Moisture $(\%)( \pm 1.8)$ & Bacteria $\left(10^{6} \mathrm{CFU} / \mathrm{g}\right)$ & Fungi $\left(10^{5} \mathrm{CFU} / \mathrm{g}\right)$ \\
\hline Initial soil & 6.2 & 413.0 & 32.0 & 1.8 & 1.0 \\
Control soil test & 6.7 & 390.0 & 27.9 & 1.5 & 1.4 \\
PP/PHBV (80/20) & 6.6 & 400.4 & 28.6 & 1.3 & 1.6 \\
PE/PHBV (80/20) & 6.6 & 400.8 & 27.6 & 1.0 & 1.5 \\
\hline
\end{tabular}

erosion from the surface to the interior, whereas PLA was hydrolytically degraded, which was the reason that it had different degradation rates at different depths of soil, where there were different moisture levels and microbial strains. ${ }^{31}$ César et al. ${ }^{32}$ studied the mineralization of poly(3-caprolactone) and adipatemodified starch blend in soils with different textures. On the basis of their analysis of the evolution of $\mathrm{CO}_{2}$, the authors concluded that the soil texture affected the kinetics of mineralization of polymers and degradation is faster in clayey soils than in sandy soils.

The influence of soil's physical and chemical parameters on microbial activity is not linear, but rather complex, and is reflected in the individual responses of the various species of microorganisms and their enzymatic systems. ${ }^{29}$ Thus, each factor directly or indirectly affects the microbiota and therefore the biodegradation of polymeric materials.

As mentioned earlier, respirometry is a method for determining the amount of carbon released in the form of $\mathrm{CO}_{2}$ in response to the action of the soil microbial community. ${ }^{33}$ Figure 2 shows the percentage of biodegradation of each sample based on the quantification of accumulated $\mathrm{CO}_{2}$ generated in each respirometer flask during the 180 days of the experiment.

In the present study, the PP/PHBV (80/20) films presented no biodegradation during the period in which they were buried in the soil. The amount of $\mathrm{CO}_{2}$ produced in the biometer flasks containing these films was less than the amount produced by the control biometer (containing only soil). The negative values relating to the amount of $\mathrm{CO}_{2}$ produced in biometer flasks containing PP/PHBV films were due to the films' inhibitory action on microbial activity. ${ }^{34}$ According to Chiellini et al., ${ }^{35}$ respiromet-

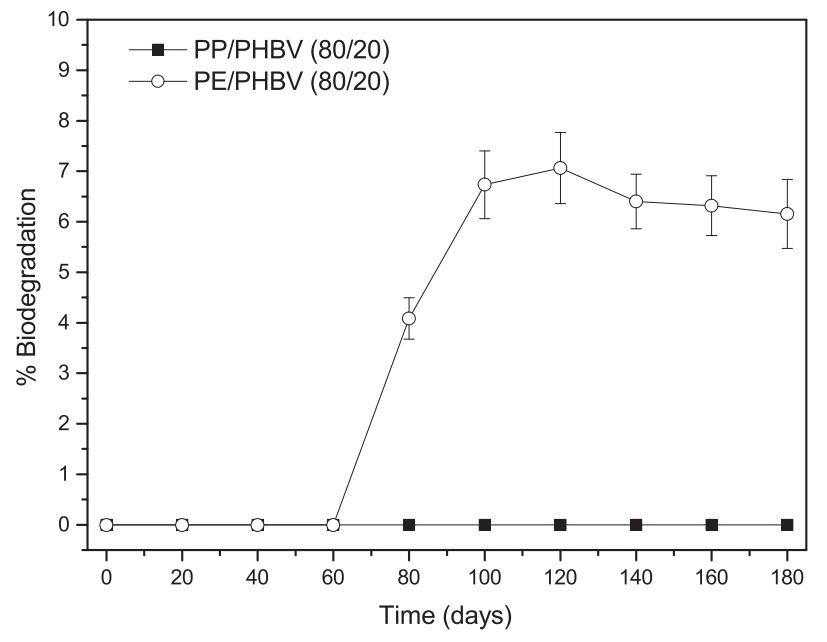

FIGURE 2. Percentage of biodegradation. ric tests may be affected by the large amount of $\mathrm{CO}_{2}$ produced in biometric controls, especially when the degradation of the samples is slow. According to these authors, depending on the amount of sample, there is an increase in local concentrations of the material, and also in the products of degradation, which can interfere negatively in the ideal conditions for microbial growth. Therefore, it is possible that due to the large lag phase and the properties of materials to be degraded in the test, the number of microorganisms was not sufficient for biodegradation. ${ }^{36}$ In addition, the soil microbial community can use the available organic matter in the soil as a cosubstrate in metabolic pathways. ${ }^{37}$

The biodegradation rate observed for the PE/PHBV (80/20) film was under $7 \%$, twice the rate observed for the neat PE. ${ }^{15}$ It was noticed that the $\mathrm{CO}_{2}$ evolution rate of $\mathrm{PE} / \mathrm{PHBV}$ samples was similar to that of the control respirometer (containing only soil) in up to 60 days, different than the films neat PE that started the $\mathrm{CO}_{2}$ evolution in 120 days. ${ }^{15} \mathrm{Ho}$ and Pometto ${ }^{38}$ also reported that the $\mathrm{CO}_{2}$ evolution rate $(\mathrm{mg})$ of $\mathrm{PE}$ samples at temperatures of 28,40 , and $55^{\circ} \mathrm{C}$ in 182 days coincided with the $\mathrm{CO}_{2}$ production rates in respirometers containing only soil. Corti et al. ${ }^{39}$ found that the amount of $\mathrm{CO}_{2}$ produced in preoxidized PE samples containing pro-oxidant additives was higher than that of the control with nonoxidized films. These authors attributed the much higher respiration rate $\left(\mathrm{CO}_{2}\right.$ production $)$ in oxidized films to fungi, which are able to use oxidation products as a source of carbon. Feuilloley et al. ${ }^{40}$ tested the biodegradation of commercial films Mater-Bi ${ }^{\circledR}$ (polycaprolactone/starch [60/40] blend, $50 \mu \mathrm{m}$ thick), Ecoflex ${ }^{\circledR}(60 \mathrm{~mm})$, and PE prooxidant additive $(36 \mathrm{mM})$. The PE films showed a degradation rate of $10-15 \%$ after 1 year of incubation at $28^{\circ} \mathrm{C}$.

Figure 3 shows FTIR spectra of the untreated and after biodegradation films in respirometric tests. The spectra of the PP/PHBV (Fig. 3a) were normalized using the band at $1456 \mathrm{~cm}^{-1}$, attributed to $\mathrm{CH}_{3}$ deformation, which is independent of crystallinity. ${ }^{41}$ The spectra of the PE/PHBV (Fig. 3b) films were normalized in relation to the band at $1465 \mathrm{~cm}^{-1}\left(\mathrm{CH}_{2}\right.$ deformation). ${ }^{42}$

After the respirometric test on the blends, several changes were detected in the bands at 1182 (C-O-C amorphous phase), 1228 (C-O-C crystalline-sensitive band), 1279 (C-O-C crystalline-sensitive band), ${ }^{43} 1724$, and $1746 \mathrm{~cm}^{-1}$ ( $\mathrm{C}=\mathrm{O}$ crystalline and amorphous phase). Variations in the FTIR spectrum occurred preferentially in the fraction of PHBV, especially the decrease in intensity of the bands at $1182 \mathrm{~cm}^{-1}(44 \%)$ and $1746 \mathrm{~cm}^{-1}$ (approximately 30\%). The biotreated films showed increased intensity of the bands at $1724 \mathrm{~cm}^{-1}$ (crystalline phase) and 1228 and $1279 \mathrm{~cm}^{-1}$ (crystallinesensitive band). The PE/PHBV blend showed greater biodegradation in the PHBV amorphous phase, due to the ester groups that were consumed, leading to rearrangement of the 


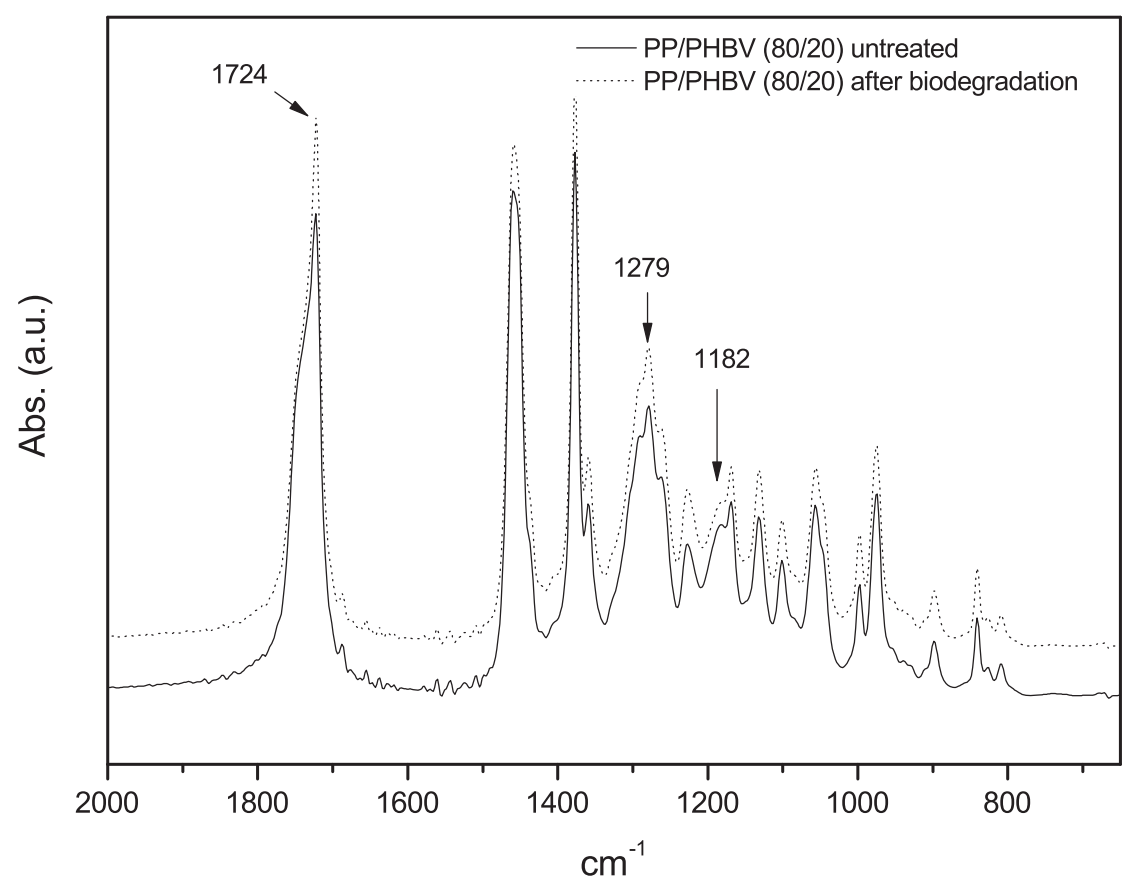

(a)

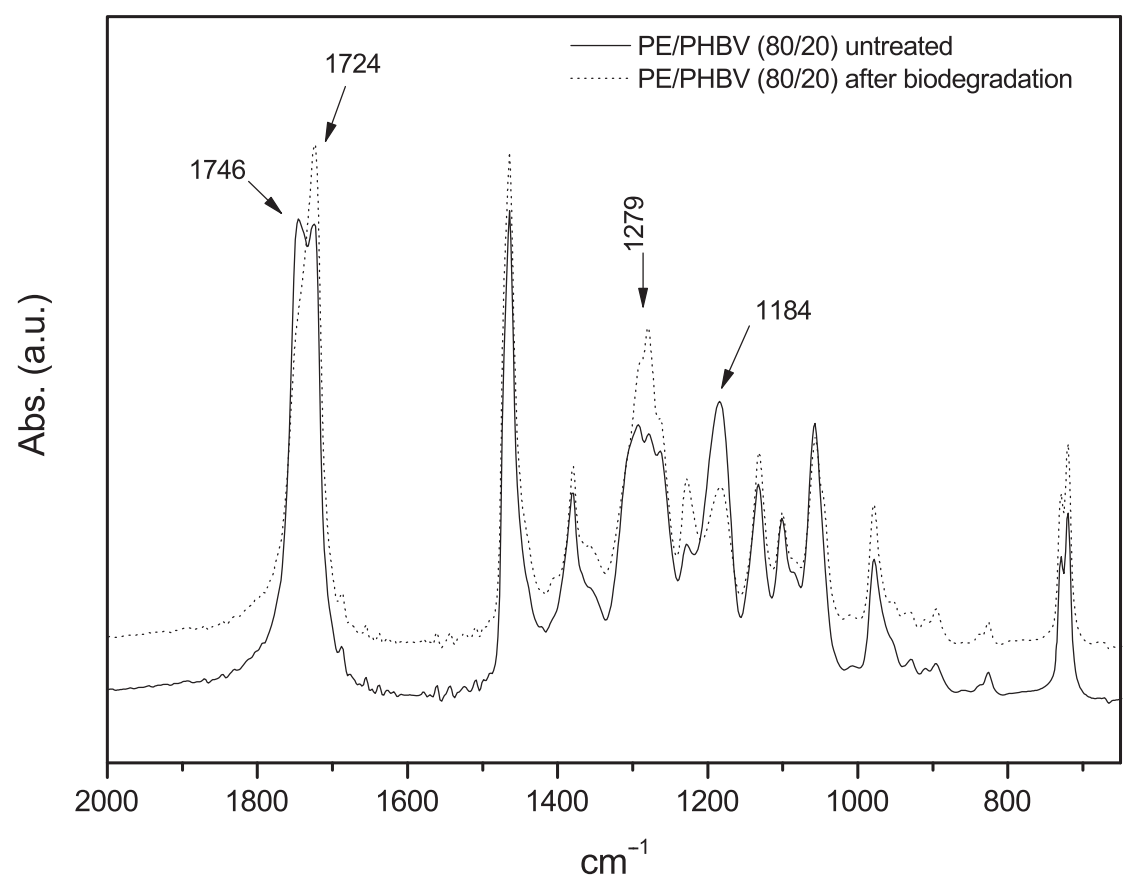

(b)

FIGURE 3. FTIR films: (a) PP/PHBV (80/20) (__ untreated ( . . . ) after biodegradation; (b) PE/PHBV (80/20) (__) untreated ( . . . ) after biodegradation.

crystalline phase of PHBV fraction. The PP/PHBV blend presented the same tendency, but lower values.

The X-ray diffractograms of the samples before and after the respirometric assay are shown in Fig. 4. Table II lists the average crystallite size $(D)$ assigned to planes (110) of PP, PE, and PHBV, calculated by Scherrer's equation ${ }^{44}$ and variation in crystallite size after biodegradation $(\% D)$. Changes significant in the degree of crystallinity were not observed after the biotreatment; the differences were $55-57 \%$ for PP/PHBV (80/20) and 54-52\% for PE/PHBV (80/20) blends, respectively.

PP/PHBV (80/20) (Fig. 4a) and PE/PHBV (80/20) (Fig. 4b) blends showed an increase in the crystallite sizes of the 


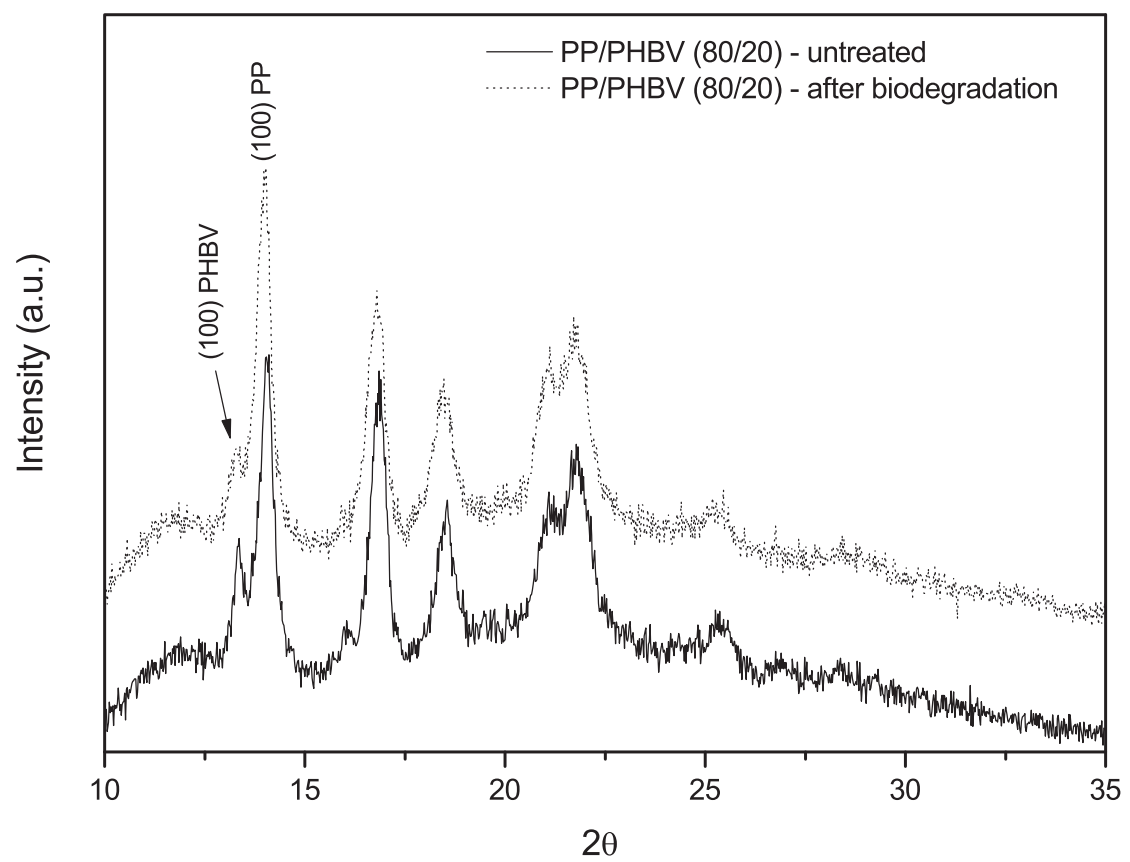

(a)

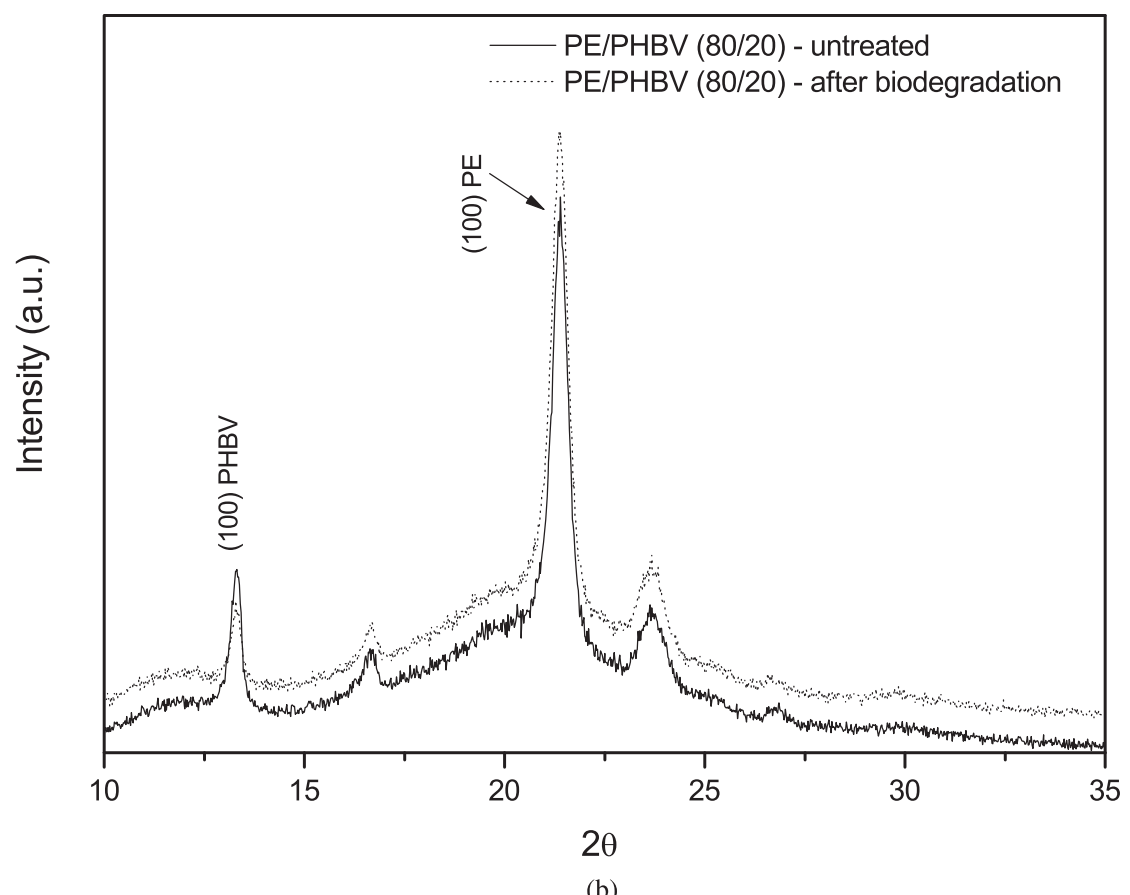

(b)

FIGURE 4. DRX films: (a) PP/PHBV (80/20) (__ untreated ( . . . ) after biodegradation; (b) PE/PHBV (80/20) (__ untreated ( . . . ) after biodegradation.

fraction of the PHBV after the respirometric test. These changes were probably due to the biodegradation of the contents of $\mathrm{HV}$ (18\% valerate), located at the edges of the PHB crystal core, as described by Yoshie et al. ${ }^{45}$ and closer to the other polymer (PE or PP). The onset of biodegradation occurred in the fraction of PHBV rather than in the interphase of the blend, as described by Gonçalves et al. ${ }^{15,16}$ The biodegradation of the PE/PHBV $(80 / 20)$ blend was higher compared with the PP/PHBV (80/20) blend; the PHBV fraction in the PE blend showed a larger crystallite size than the PHBV in the PP blend; thus, these two blends present different interphases. Both factors, different dispersion of the PHBV fraction in the PE and PP matrix and different phase separation in the two blends, influence the biodegradation process. ${ }^{15}$ The thermal and mechanical properties of the 
TABLE II

Crystallite Size $(D)$ and Variation on Crystallite Size after Biodegradation $(\% D)$

\begin{tabular}{|c|c|c|c|c|c|}
\hline \multirow[b]{2}{*}{ Sample } & \multirow[b]{2}{*}{$2 \theta$} & \multirow[b]{2}{*}{$h k l$} & \multicolumn{2}{|c|}{$D(\mathrm{~nm})$} & \multirow[b]{2}{*}{$\% D$} \\
\hline & & & Untreated & After Biodegradation & \\
\hline \multirow[t]{2}{*}{ PP/PHBV } & 13.3 & (110) PHBV & 3.79 & 4.02 & $\uparrow 6.0$ \\
\hline & 14.0 & (110) PP & 3.53 & 3.19 & $\downarrow 10.0$ \\
\hline \multirow[t]{2}{*}{ PE/PHBV } & 13.3 & (110) PHBV & 4.40 & 5.43 & $\uparrow 23.0$ \\
\hline & 21.4 & (110) PE & 3.18 & 3.03 & $\downarrow 5.0$ \\
\hline
\end{tabular}

$\uparrow$, increase crystallite size after biodegradation; $\downarrow$, decrease crystallite size after biodegradation.

polymeric composites oxo-biodegradable PE and lignin (PE/lignin) studied by Samal et al. ${ }^{11}$ showed morphological incompatible characteristics attributed to the heterogeneous dispersion of the lignin phase in PE and the poor interfacial adhesion with the PE matrix. ${ }^{11}$ According to Rosa et al., ${ }^{46}$ blends of $\mathrm{PHB} / \mathrm{LDPE}$ at different proportions were immiscible and showed phase separation. The polymeric spheres in the blend containing 25\% LDPE were larger, whereas the blend containing $50 \%$ LDPE had higher polymer dispersion and smaller spheres. There was poor interfacial adhesion between PHB and LDPE, and the spheres of LDPE were not retained in the PHB matrix. ${ }^{45}$ The same results have been observed by Burlein and Rocha ${ }^{47}$ in LDPE/PHB blends. These results were attributed to the immiscibility of polymers and the weak interfacial adhesion between the two polymers. Significant differences in morphology of the LDPE/PHB blends were observed as the PHB concentration was increased. ${ }^{47}$
The SEM micrographs (Fig. 5) illustrate the morphological changes in the materials, resulting from microbial attack on polymer surfaces. After 180 days of biodegradation, the morphology changed significantly in the PP/PHBV and PE/PHBV films. This result, associated with the changes shown by FTIR and $\mathrm{XRD}$, suggests that microbial attack changed the properties of the polymer matrix.

The biodegradation of blends is a process that depends on the phase distribution and compatibilization between the polymers. The use of the biodegradable fraction polymer and interphase by microorganisms causes changes in the polymeric matrix. The same behavior was reported by Masood et al., ${ }^{17}$ who observed a crystallinity increase in the PP/PHBV (90/10) blend subjected to microbial consortium in controlled biological and soil environments. According to these authors, the beginning of the degradation occurred in the PHBV content of the blend due to surface erosion caused by the microorganism, which is
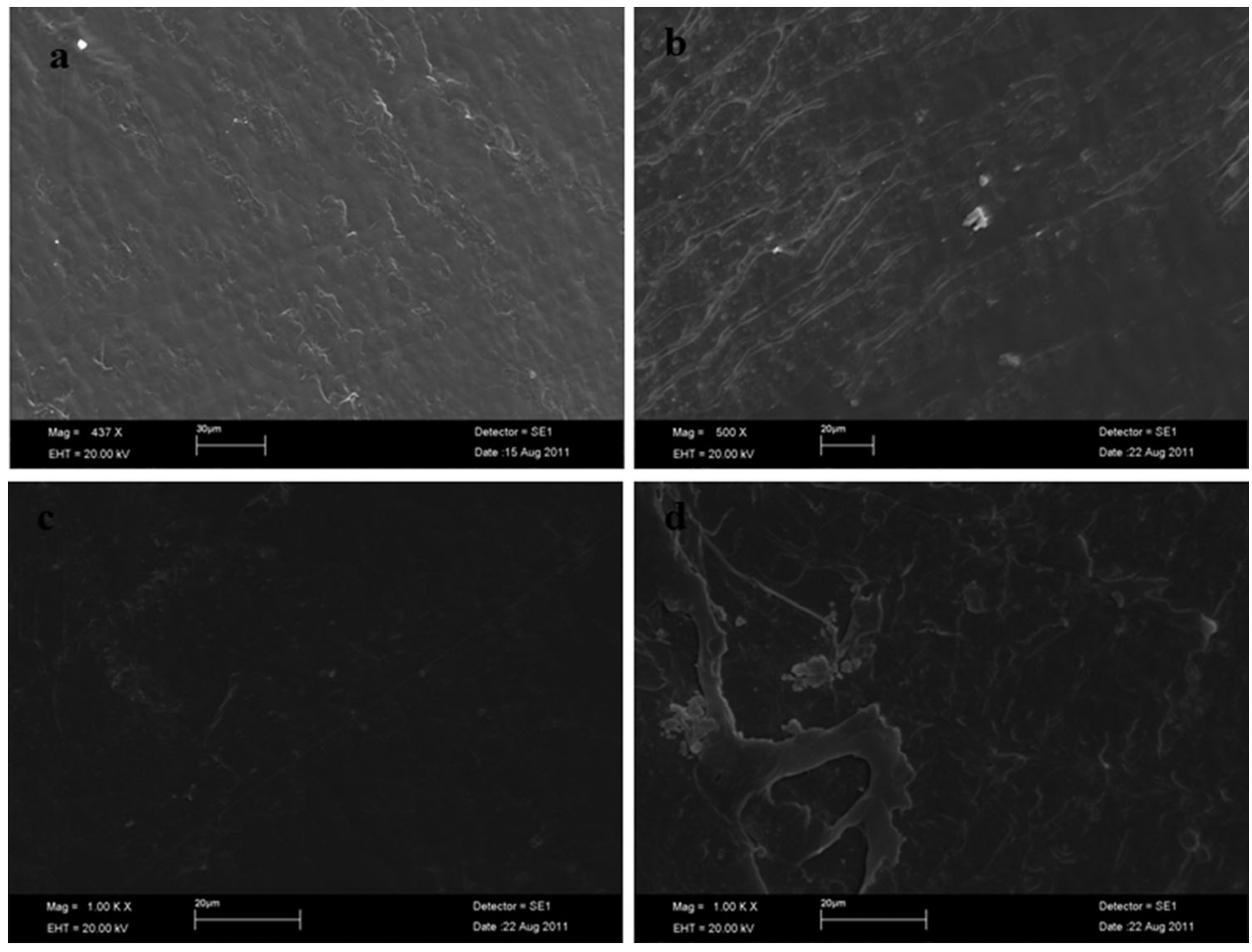

FIGURE 5. SEM micrographs of (a) PP/PHBV (80/20) untreated, (b) PP/PHBV (80/20) after biodegradation, (c) PE/PHBV (80/20) untreated, and (d) PE/PHBV (80/20) after biodegradation films. 


\section{RESEARCH ARTICLE}

gradually propagated to the inside of blend, affecting its chemical structure. ${ }^{17}$

It is important to consider the structural and chemical parameters of each polymeric material used, such as its hydrophobicity, degree of crystallinity (crystal size), and morphology, which influence microbial activity. ${ }^{5,48-50}$ However, in the blends, a main factor that influence the biodegradation process is the compatibility between the phases of the polymer fractions involved. That is, a higher phase separation makes the material more susceptible to microbial attack.

\section{Conclusions}

The films were biodegraded in the following order: PE/PHBV $(80 / 20)>\mathrm{PP} / \mathrm{PHBV}(80 / 20)$. The rate of biodegradation of PE/PHBV was doubled and the beginning occurred in half the time than the neat PE film. The morphology (phase separation) in the blend is a relevant factor to support the biodegradation process. The bacterial population in the soil containing PP/PHBV and PE/PHBV decreased. However, the fungal population increased after 180 days of biodegradation.

The respirometry test is an efficient method to assess the biodegradability of polymeric films. It is a method that, associated with FTIR and XRD, assists in the understanding of biodegradation in the soil.

\section{References}

1. Gu, J.-D. Int Biodeterior Biodegrad 2003, 52, 69.

2. Madigan, M. T.; Martinko, J. M.; Parker, J. (Eds.). 10th ed.; Brock biology of microorganisms Pearson: São Paulo, Brazil, 2004.

3. Briassoulis, D.; Dejean, C. J Polym Environ 2010, 18, 384.

4. Briassoulis, D.; Dejean, C.; Picuno, P. J Polym Environ 2010, 18, 364.

5. Eubeler, J. P.; Bernhard, M.; Zok, S.; Knepper, T. P. Trends Anal Chem 2009, 28, 1057.

6. Gu, J-G.; Gu, J.-D. J Polym Environ 2005, 13, 65.

7. Krzan, A.; Hemjinda, S.; Miertus, S.; Corti, A.; Chiellini, E. Polym Degrad Stab 2006, 91, 2819.

8. Bastioli, C. (Ed.). Handbook of Biodegradable Polymers, 1st ed; Rapra Technology: Shawbury UK, 2005.

9. Lopes, A. R.; Faria, C.; Prieto-Fernández, A.; Trasar-Cepeda, C.; Manaia, C. M.; Nunes, O. C. Soil Biol Biochem 2011, 43, 115.

10. Arutchelvi, J.; Sudhakar, M.; Arkatkar, A.; Doble, M.; Bhaduri, S.; Uppara, P. V. Indian J Biotechnol 2008, 7, 9.

11. Samal, S. K.; Fernandes, E. G.; Corti, A.; Chiellini, E. J Polym Environ 2014, 22, 58.

12. Laycock, B.; Halley, P.; Pratt, S.; Werker, A.; Lant, P. Prog Polym Sci 2013, 38, 536.

13. Kabe, T.; Sato, T.; Kasuya, K.; Hikima, T.; Takata, M.; Iwata, T. Polymer 2014, 55,271
14. Zembouai, I.; Kaci, M.; Bruzaud, S.; Benhamida, A.; Corre, Y. M.; Grohens, Y. Polym Test 2013, 32, 842.

15. Gonçalves, S. P. C.; Martins-Franchetti, S. M. Int J Mat Sci 2013, 2, 54

16. Gonçalves, S. P. C.; Martins-Franchetti, S. M.; Chinaglia, D. L. J Polym Environ $2009,17,280$

17. Masood, F.; Yasin, T.; Hameed, A. Int Biodeterior Biodegrad 2014, 87, 1.

18. Gómez, E. F.; Michel, F. C. Jr. Polym Degrad Stab 2013, 12, 2583.

19. Ammala, A.; Bateman, S.; Dean, K.; Petinakis, E.; Sangwan, P.; Wong, S.; Yuan, Q.; Yu, L.; Patrick, C.; Leong, K. H. Prog Polym Sci 2011, 36, 1015.

20. Saad, G. R.; Seliger, H. Polym Degrad Stab 2004, 83, 101.

21. Weng, Y. X.; Wang, X. L.; Wang, Y. Z. Polym Test 2011; 30, 372-380.

22. Centro de Pesquisas Meteorológicas e Climáticas Aplicadas à Agricultura-CEPAGRI. Available at: http://www.cpa.unicamp.br/outrasinformacoes/clima_muni_494.html. Accessed June 1, 2013.

23. Empresa Brasileira de Pesquisa Agropecuária (EMBRAPA). Manual de métodos de análise do solo; SNLCS: Rio de Janeiro, Brazil, 1997.

24. Pereira, M. G.; Valladares, G. S.; Anjos, L. H. C.; Benites, V. M.; Espíndula, A. Jr.; Ebeling, A. G. Sci Agric 2006, 63, 187.

25. Jahnel, M. C.; Cardoso, E. J. B. N.; Dias, C. T. S. Rev Bras Cienc Solo 1999, 23 553.

26. Bartha, R.; Pramer, D. J Soil Sci 1965, 100, 68.

27. International Organization for Standardization. ISO 14855-2. 2009.International Organization for Standardization: Geneva, Switzerland.

28. Kang, H.; Kang, S.; Lee, D. Ecol Res 2009, 25, 1137.

29. Paul, E. A. (Ed.): 3th ed.; Soil microbiology, ecology, and biochemistry Elsevier: Oxford, UK, 2007.

30. Rychter, P.; Biczak, R.; Herman, B.; Smylla, A.; Kurcok, P. Adamus, G.; Kowalczuk, M. Biomacromolecules 2006, 7, 3125.

31. Weng, Y.-X.; Wang, L.; Zhang, M.; Wang, X. L.; Wang, Y. Z. Polym Test 2013, 32, 60.

32. César, M. E. F.; Mariani, P. D. S. C.; Innocentini-Mei, L. H.; Cardoso, E. J. B. N. Microbiota do Solo e Qualidade Ambiental Polym Test 2009, 28, 680.

33. Silveira, A. P. D.; Freitas, S. S. (Eds.). IAC: Campinas, Brazil, 2007.

34. Campos, A.; Marconato, J. C.; Martins-Franchetti, S. M. Polim Cienc Tecnol 2010, 20, 295.

35. Chiellini, E.; Corti, A.; Swift, G. Polym Degrad Stab 2003, 81, 341.

36. Reuschenbach, P.; Pagga, U.; Strotmann, U. Water Res 2003, 37, 1571.

37. van der Zee, M.; Stoutjesdijk, J. H.; Feil, H.; Feijen, J. Chemosphere 1998, 36, 461.

38. Ho, K. L. G.; Pometto, A. L. J Environ Polym Degrad 1999, 7, 101.

39. Corti, A.; Muniyasamy, S.; Vitali, M.; Imam, S. H.; Chiellini, E. Polym Degrad Stab 2010, 95, 1106.

40. Feuilloley, P.; César, G.; Benguigui, L.; Grohens, Y.; Pillin, I.; Bewa, H.; Lefaux, S.; Jamal, M. J Polym Environ 2005, 13, 349.

41. Arkatkar, A.; Juwarkar, A. A.; Bhaduri, S.; Uppara, P. V.; Doble, M. Int Biodeterior Biodegrad 2010, 64, 530.

42. Sudhakar, M.; Doble, M.; Murthy, P. S.; Venkatesan, R. Int Biodeterior Biodegrad 2008, 61, 203.

43. Reis, K. C.; Pereira, J.; Smith, A. C.; Carvalho, C. W. P.; Wellner, N.; Yakimets, I. J Food Eng 2008, 89, 361.

44. Munaro, M.; Akcelrud, L. Polym Degrad Stab 2008, 93, 43.

45. Yoshie, N.; Saito, M.; Inoue, Y. Macromolecules 2001, 34, 8953.

46. Rosa, D. S.; Gaboardi, F.; Guedes, C. G. F.; Calil, M. R. J Mater Sci 2007, 42, 8093.

47. Burlein, G. A. D.; Rocha, M. C. G. Mat Res 2014, 17, 203.

48. Eldsater, C.; Erlandsson, B.; Renstad, R.; Albertsson, A. C.; Karlsson, S. Polymer 2000, 41, 1297.

49. Gonçalves, S. P. C.; Martins-Franchetti, S. M. J Polym Environ 2010, $18,714$.

50. Vilaplana, F.; Strömberg, E.; Karlsson, S. Polym Degrad Stab 2010, 95, 2147. 